\title{
Deformation Response of Bimodal Nanoscale Metallic Multilayers
}

\author{
A. Misra*, X. Zhang** and R. Dickerson*, \\ * Materials Science and Technology Division, Los Alamos National Laboratory, NM 87545 \\ ** Now at: Dept. of Mechanical Engineering, Texas A\&M University, College Station, TX 77843
}

Sputter deposited, self-supported $\mathrm{Cu}-\mathrm{Nb}$ multilayered foils were room temperature rolled to study the effect of nanostructuring on the deformation and fracture behavior at large plastic strains. At layer thickness of a few tens of nanometers, with as-deposited yield strengths exceeding $1 \mathrm{GPa}, \mathrm{Cu}-$ $\mathrm{Nb}$ multilayers exhibited extraordinary plastic stability undergoing uniform reduction in layer thickness of both $\mathrm{Cu}$ and $\mathrm{Nb}$ to high levels of plastic strain [1]. However, at layer thickness of a few nanometers, with as-deposited yield strengths exceeding $2 \mathrm{GPa}$, fracture by shear localization was observed at rolling reductions of only a few percent [2]. In this investigation, deformation response of bimodal multilayers is characterized. A multilayered stack of $40 \mathrm{~nm} \mathrm{Cu} / 40 \mathrm{~nm} \mathrm{Nb} / 4 \mathrm{~nm} \mathrm{Cu} / 4$ $\mathrm{nm} \mathrm{Nb}$ layers was repeated 175 times during sputter deposition to produce $15.4 \mu \mathrm{m}$ thick coatings that were peeled off from the glass substrates, sandwiched between stainless steel sheets and rolled at room temperature. In the as-deposited state, the foils exhibited a textured, nanocrystalline structure (Fig. 1a) with Kurdjumov-Sachs orientation relationship: $\{110\} \mathrm{Nb} / /\{111\} \mathrm{Cu}$ and $<111>\mathrm{Nb} / /<110>\mathrm{Cu}$ (Fig. 1b). Unlike the $4 \mathrm{~nm} \mathrm{Cu} / 4 \mathrm{~nm} \mathrm{Nb}$ multilayers that developed through thickness cracks in the first rolling pass of $\approx 5 \%$ reduction strain, the $40 \mathrm{~nm} \mathrm{Cu} / 40 \mathrm{~nm} \mathrm{Nb} / 4 \mathrm{~nm} \mathrm{Cu}$ $/ 4 \mathrm{~nm} \mathrm{Nb}$ bimodal multilayers exhibited no shear cracks after $20 \%$ reduction in rolling.

Bright field (BF) transmission electron microscopy (TEM) image of the rolled bimodal multilayer (Fig. 2a) shows uniform reduction in layer thickness with no dislocation cell structure formation that was previously reported in $\mathrm{Cu}-\mathrm{Nb}$ multilayers with micrometer-scale layers [2]. Thus, deformation mechanisms in nanolayered composites are such that dislocation cell structures do not form. Furthermore, diffraction patterns (Fig. 2b) indicate that the initial texture is preserved. Fig. 2a also shows that the $4 \mathrm{~nm} \mathrm{Cu}$ and $\mathrm{Nb}$ layers co-deform with the $40 \mathrm{~nm}$ layers, i.e., no clear evidence of decohesion or shear cracking was observed. However, from the bright field images it is not clear if the $4 \mathrm{~nm}$ layers still have chemically sharp layers after rolling. Energy dispersive spectroscopy (EDS) line scan in a TEM with $\approx 1 \mathrm{~nm}$ probe size (Fig. 3) clearly shows the chemically discrete layers. High-resolution TEM image (Fig. 4) of the rolled material indicates crystalline layers supporting the EDS data that indicated no significant intermixing of the immiscible $\mathrm{Cu}$ and $\mathrm{Nb}$ layers across the interface. Some grains in $\mathrm{Cu}$ layers showed nanoscale twinning (Fig. 5) in the rolled sample. However, such twinning was also observed in the as-deposited samples and is likely to be growth-induced. In summary, this work highlights the unique deformation characteristics of nanolayered metals: uniform reduction in layer thickness to large plastic strains with no cell structure formation and no change in out-of-plane initial texture, and the stable co-deformation of layers as thin as $4 \mathrm{~nm}$ when constrained with relatively thicker $40 \mathrm{~nm}$ layers. Bimodal nanoscale multilayers may offer the best combination of high strength and plastic deformability in nanolayered systems.

Reference:

[1] A. Misra, J.P. Hirth, R.G. Hoagland, J.D. Embury and H. Kung, Acta Mater., 52, (2004) 2387.

[2] A. Misra, et al., Int. Journal of Damage Mechanics, 12, (2003), 365.

[3] This research is funded by DOE, Office of Science, Office of Basic Energy Sciences. 

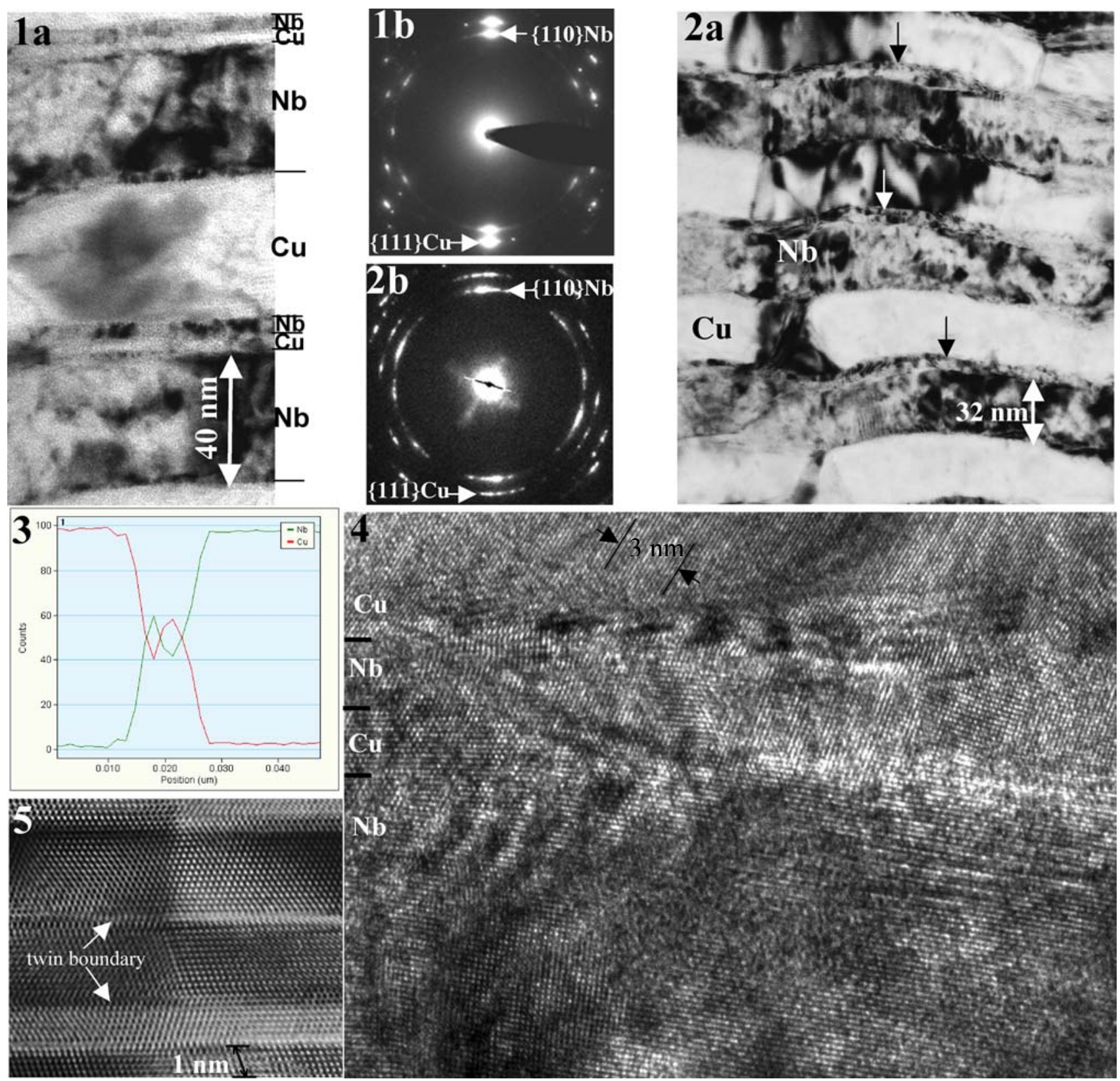

Fig. 1 (a) BF TEM image and (b) corresponding selected area diffraction pattern (SADP) of a sputter-deposited $40 \mathrm{~nm} \mathrm{Cu} / 40 \mathrm{~nm} \mathrm{Nb} / 4 \mathrm{~nm} \mathrm{Cu} / 4 \mathrm{~nm} \mathrm{Nb}$ multilayer.

Fig. 2 (a) BF TEM image and (b) corresponding SADP of a $40 \mathrm{~nm} \mathrm{Cu} / 40 \mathrm{~nm} \mathrm{Nb} / 4 \mathrm{~nm} \mathrm{Cu} / 4 \mathrm{~nm}$ $\mathrm{Nb}$ multi-layers rolled to $\approx 20 \%$ reduction. Arrows indicate the location of the $4 \mathrm{~nm}$ layers.

Fig. 3 EDS line scale, with a nanometer probe size, from the rolled sample.

Fig. 4 HRTEM image showing crystalline layers and co-deformation of the $4 \mathrm{~nm}$ layers with the 40 nm layers after rolling.

Fig. 5 HRTEM image of growth-induced nanoscale twins in the $\mathrm{Cu}$ layer. 